\title{
The Pattern of Cervical Cancer according to HIV Status in Yaoundé, Cameroon
}

\author{
Pierre-Marie Tebeu $\mathbb{D}^{1,2,3}$ Jean Pierre Ngou-Mve-Ngou, ${ }^{4}$ Laure Leka Zingué, ${ }^{2}$ \\ Jesse Saint Saba Antaon $\mathbb{D}^{\mathbb{2}, 3}{ }^{2,3}$ Etienne Okobalemba Atenguena, ${ }^{5}$ and Julius Sama Dohbit ${ }^{1}$ \\ ${ }^{1}$ Department of Obstetrics and Gynaecology, Faculty of Medicine and Biomedical Sciences, University of Yaoundé I, \\ Yaoundé, Cameroon \\ ${ }^{2}$ League of Initiative and Active Research for Women's Health and Education (LIRASEF), Yaoundé, Cameroon \\ ${ }^{3}$ Inters-states Centre for Public Health Training in Central Africa, Brazzaville, Congo \\ ${ }^{4}$ Department of Obstetrics \& Gynecology, University Hospitals, Libreville, Gabon \\ ${ }^{5}$ Department of Internal Medicine, Faculty of Medicine and Biomedical Sciences, University of Yaounde I, Yaoundé, Cameroon
}

Correspondence should be addressed to Pierre-Marie Tebeu; pmtebeu@yahoo.fr and Jesse Saint Saba Antaon; antaonjessesaintsaba@gmail.com

Received 11 August 2021; Revised 8 September 2021; Accepted 20 September 2021; Published 13 October 2021

Academic Editor: Enrique Hernandez

Copyright (c) 2021 Pierre-Marie Tebeu et al. This is an open access article distributed under the Creative Commons Attribution License, which permits unrestricted use, distribution, and reproduction in any medium, provided the original work is properly cited.

\begin{abstract}
Objective. To analyze the epidemiological aspects of invasive cervical cancer according to HIV status. Methods. This was an historical cohort study from January 2010 to April 2017 in three hospitals at the Yaoundé city Capital, Cameroon, after the National Ethics Committee' approval. We included invasive cervical cancers with documented HIV status. Odds ratios and $95 \%$ confidence interval were calculated to assess the association between the different variables and HIV status. Survival was analyzed using the Kaplan-Meier. The level of significance was set up at $<5 \%$. Results. Among the overall 213 cervical cancer patients, 56 were HIV+ (24.67\%). Factors associated with positive HIV status were age below 40 (OR: 2.03 (1.38-2.67)), celibacy (OR: 2.88 (1.58-4.17)), nonmenopausal status (OR: 2.56 (1.36-3.75)), low parity, primiparity (OR: 2.59 (1.43-3.74)), and for parity with 2-4 children (OR: 2.24 (1.35-3.12)). Concerning the HIV+ patients, tumor was diagnosed late (stages III-IV) (OR: 2.70 (1.43-5.08)), undifferentiated (grade III) (OR: 7.69 (5.80-9.57)), with low median survival (9.83 months vs. 20.10 months). Conclusion. HIV is frequent among cervical cancer patients. In the HIV+ patients, the diagnosis was made at the advanced stage, cells were poorly differentiated, and the prognosis was worse.
\end{abstract}

\section{Introduction}

Cervical cancer is a malignant neoformation developed at the opening of the cervix, most often on the exocervical mucosa [1]. Cervical cancer starts by a precancerous lesion known as benign and asymptomatic epithelial abnormality. Proper management of these precancerous lesions prevents development towards invasive cancer $[1,2]$.

In resource-limited countries, cervical cancer is the second leading cause of death from cancer in women, after breast cancer [1]. This sexually transmitted disease progresses very slowly between 10 and 20 years from infection to premalignant and malignant lesion giving a great possibility of screening [2]. In 2018, GLOBOCAN estimated that there were more than 570,000 new cases diagnosed a year, and 311,000 women die during the same period [3]. GLOBOCAN also estimated that there were more than 32,000 new cases of cervical cancer in Central Africa, with about 23,000 deaths during the same year [3].

There is a wide geographical disparity in the distribution of cervical cancer worldwide, with over $85 \%$ of cases in developing countries [3]. This disparity in geographical distribution of cervical cancer, with high morbidity and mortality in developing countries, is mainly due to the 
absence of systematic screening for this cancer and comorbidity with the advent of HIV/AIDS pandemic in these poor regions $[3,4]$.

$\mathrm{HIV}$ infection is also a real public health issue worldwide and mainly in African countries leading to critical consequences, including morbidity and mortality [4]. HIV infection generally increases the risk of cancer and mainly the viral-induced one [4]. Many studies documented that HIV infection and the subsequent immunodeficiency are associated with increased risk of precancerous lesions [4-6]. Therefore, HIV-infected women are 4-9 times more likely to develop cervical cancer $[7,8]$. In 1993, the revised classification by CDC (Centre of Disease's Control and Prevention), included the invasive carcinoma of the cervix among the diseases that move from HIV's infection stage to AIDS disease one [9].

In Cameroon, cervical cancer is the second cancer in women, just after breast cancer $(25.2 \%$ vs. $35.1 \%)$ [3]. Moreover, in some series, cervical cancer stands before breast cancer $[10,11]$. In the same country, HIV has a prevalence of $1.9 \%$ in men aged $15-64$ and $3.6 \%$ in women of the same age group [12].

Little is known about the coexistence of the two diseases in Cameroon.

1.1. Objective. To analyze the epidemiological aspects of invasive cervical cancer according to HIV status in Yaoundé, Cameroon.

\section{Materials and Methods}

2.1. Type-Place-Period. This is an historical cohort study over a 7-year period (January 2010-April 2017) in Yaoundé, Cameroon. The three study sites were Yaoundé University Hospital Centre (YUTH), Yaoundé General Hospital (YGH), and Yaounde Gynaeco-Obstetric and Paediatric Hospital (YGOPH). The study was approved by these hospitals.

2.2. Study Population. The study population included women in whom invasive cervical cancer was detected. After obtaining their verbal consent, all patients with invasive cervical cancer with documented histological diagnosis and HIV status were included.

2.3. Variables. Data on HIV status, sociodemographic, reproductive, clinical, and therapeutic characteristics of patients were collected. Data collection was done from medical records and phone calls after verbal consent.

2.4. Data Analysis. The data were analyzed using Epi-Info 7.2.2.6 software (CDC, USA) and SPSS 20.0 software (IBM, Armonk, NY, USA). The absolute and relative frequencies as well as central tendency (mean and median) and dispersions parameters were calculated. The odds ratios were calculated within 95\% confidence interval in order to assess the influence between the different variables and HIV status. The dependent variables considered were the HIV status of patients with invasive cervical cancer and the survival period. Pearson, Fisher, and Wald statistical tests were used. The level of significance was set up at $p<5 \%$.

\section{Results}

A total of 213 invasive cervical cancer patients were recorded, including 56 with $\mathrm{HIV}+$ status (24.67\%). The median age of invasive cervical cancer patients was 12 years lower for HIV+ patients compared to their HIV- status counterparts ((43 vs. 55 years); $p<0.001)$.

$\mathrm{HIV}+$ patients were frequently received at advanced cancer stage (FIGO III-IV (57, 15\% vs. $32.48 \%)$ ). Squamous cell carcinoma was the histological type mostly found in both groups (87.5\% HIV+ status vs. $89.81 \%$ for HIV- one). Cancer in HIV+ women was mostly with undifferentiated cells $(35.7 \%$ vs. $3.82 \%)$.

Younger cervical cancer patients $(<40$ years old) were more likely to be HIV + than elder ones (40-60 years) $(54.7 \%$ vs. $28.9 \%$; OR: 2.03 (1.38-2.67); $p=0.017)$. Single/divorced cervical cancer women were more at risk of being HIV+ than married ones (46.6\% vs. 16.1\%, OR: 2.88 (1.58-4.17), $p=0.037 ; 16.1 \%$ vs. $50 \%$, OR: $3.08(1.69-4.46), p=0.023)$ (Table 1).

Premenopausal women were 2.56 times more likely to be $\mathrm{HIV}+$ than postmenopausal ones $(17.14 \%$ vs. $43.84 \%$, OR: $2.56(1.36-3.75), p=0.016)$.

Lower/mild parity women ( $<5$ children) had more risk of being HIV+ than high parity ones $(58.82 \%$ vs. $84.10 \%$, OR: 2.59 (1.43-3.74), $p=0.0016$ and $56.25 \%$ vs. $84.10 \%$, OR: 2.59 (1.43-3.74), $p=0.001)$.

Women with more than five cumulative sexual partners were more at risk of being $\mathrm{HIV}+(21.57 \%$ vs. $48.39 \%$, OR: 2.24 (1.35-3.12), $p=0.005$ ) (Table 2).

FIGO stages III-IV cervical cancer patients were more likely to be HIV+ status than those of stages I-II ( $40.51 \%$ vs. 18.85\%, OR: 2.70 (1.43-5.08), $p=0.001)$.

Compared to patients with good differentiation cell (grade I), patients with poor differentiation (grades II and III) had more risk of being HIV+ status (10\% vs. $41.94 \%$ OR: $4.19(3.16-5.21), p=0.041)$ and $(10 \%$ vs. $72.96 \%, \mathrm{OR}=7.69$ (5.80-9.57), $p=0.005$ ) (Table 3).

$\mathrm{HIV}+$ cervical cancer patients had a median survival lower than the HIV- patients (9.83 months; 95\% CI (8.32-11.3) vs. 20.10 months; 95\% CI (15.33-24.9)) (Figure 1).

\section{Discussion}

We found an HIV frequency of $24.67 \%$ in cases of invasive cervical cancer; therefore, about 1 out of 4 women was $\mathrm{HIV}+$. In Cameroon, the average frequency of HIV infection (reported by the 2018 Demographic Health Survey) is 2.9\%, with some gender disparities: $1.9 \%$ in men and $3.6 \%$ in women [12]. The high frequency of HIV-positive status among patients with invasive cervical cancer compared to HIV prevalence in the general population in women may be due to the fact that HIV infection increases the risk of 
TABLE 1: Distribution of the sociodemographic characteristics of ICC patients according to the HIV status in bivariate analysis.

\begin{tabular}{|c|c|c|c|c|c|}
\hline \multirow[b]{2}{*}{ Variables } & \multicolumn{3}{|c|}{ HIV status } & \multirow[b]{2}{*}{ OR $(95 \% \mathrm{CI})$} & \multirow[b]{2}{*}{$P$ value } \\
\hline & $\begin{array}{c}\text { Total } \\
N=213\end{array}$ & $\begin{array}{c}\mathrm{HIV}+ \\
N=56 \\
n(\%)\end{array}$ & $\begin{array}{c}\mathrm{HIV}- \\
N=157 \\
n(\%)\end{array}$ & & \\
\hline \multicolumn{6}{|l|}{ Age at diagnosis of ICC } \\
\hline$<40$ & 42 & $23(54.7)$ & $19(45.24)$ & $2.03(1.38-2.67)$ & 0.017 \\
\hline $40-60$ & 114 & $33(28.9)$ & $81(71.05)$ & $1^{\mathrm{a}}$ & \\
\hline$>60$ & 57 & $0(0)$ & $57(100)$ & 0 & 0.996 \\
\hline \multicolumn{6}{|l|}{ Profession } \\
\hline Employee/self-employment & 47 & $14(29.7)$ & $33(70.21)$ & $1.35(0.19-2.5)$ & 0.997 \\
\hline Official & 22 & $6(27.27)$ & $16(72.73)$ & $1.24(0.18-2.29)$ & 0.653 \\
\hline Unemployed & 127 & $28(22.0)$ & $99(77.95)$ & 1 & \\
\hline Not specified & 17 & $8(47.06)$ & $9(52.94)$ & & \\
\hline \multicolumn{6}{|l|}{ Educational level } \\
\hline Primary & 67 & $10(14.9)$ & $57(85.07)$ & 1 & \\
\hline Secondary & 90 & $33(36.6)$ & $57(63.33)$ & $2.46(0.95-3.96)$ & 0.227 \\
\hline Superior & 13 & $2(15.38)$ & $11(84.62)$ & $1.03(0.40-1.65)$ & 0.077 \\
\hline Not specified & 43 & $11(25.58)$ & $32(74.42)$ & & \\
\hline \multicolumn{6}{|l|}{ Marital status } \\
\hline Single & 45 & $21(46.6)$ & $24(54.33)$ & $2.88(1.58-4.17)$ & 0.037 \\
\hline Married & 105 & $17(16.1)$ & $88(83.80)$ & 1 & \\
\hline Separated/divorced & 4 & $2(50)$ & $2(50)$ & $3.08(1.69-4.46)$ & 0.023 \\
\hline Widow & 48 & $11(22.9)$ & $37(77.09)$ & $1.41(0.77-2.04)$ & 0.177 \\
\hline Not specified & 11 & $5(45.45)$ & $6(54.55)$ & & \\
\hline \multicolumn{6}{|l|}{ Place of residence } \\
\hline Urban & 148 & $45(30.4)$ & $103(69.59)$ & $3.66(1.14-6.17)$ & 0.029 \\
\hline Rural & 36 & $3(8.33)$ & $33(91.67)$ & 1 & \\
\hline Not specified & 29 & $8(27.59)$ & $21(72.41)$ & & \\
\hline
\end{tabular}

${ }^{\mathrm{a}}$ Reference category.

TABLE 2: Reproductive characteristics distribution of ICC patients based on HIV status in bivariate analysis.

\begin{tabular}{|c|c|c|c|c|c|}
\hline \multirow[b]{2}{*}{ Variables } & \multicolumn{3}{|c|}{ HIV status } & \multirow[b]{2}{*}{ OR $(95 \% \mathrm{CI})$} & \multirow[b]{2}{*}{$P$ value } \\
\hline & $\begin{array}{c}\text { Total } \\
N=213\end{array}$ & $\begin{array}{c}\mathrm{HIV}+ \\
N=56 \\
n(\%)\end{array}$ & $\begin{array}{c}\mathrm{HIV}- \\
N=157 \\
n(\%)\end{array}$ & & \\
\hline \multicolumn{6}{|l|}{ Menopause } \\
\hline Yes & 140 & $24(17.14)$ & $116(82.86)$ & $1^{\mathrm{a}}$ & - \\
\hline No & 73 & $32(43.84)$ & $41(56.16)$ & $2.56(1.36-3.75)$ & 0.016 \\
\hline \multicolumn{6}{|l|}{ Parity } \\
\hline 1 & 17 & 7 (41.18) & $10(58.82)$ & $2.59(1.43-3.74)$ & 0.016 \\
\hline $2-5$ & 64 & $28(43.75)$ & $36(56.25)$ & $2.75(1.52-3.97)$ & 0.001 \\
\hline $5-14$ & 132 & $21(15.9)$ & $111(84.10)$ & 1 & - \\
\hline \multicolumn{6}{|l|}{ Gravidity } \\
\hline $0-5$ & 59 & $25(42.37)$ & $34(57.63)$ & $2.1(0.85-3.34)$ & 0.194 \\
\hline $5-18$ & 154 & $31(20.13)$ & $123(79.87)$ & 1 & - \\
\hline \multicolumn{6}{|l|}{ Number of $\mathrm{CSP}^{\mathrm{b}}$} \\
\hline 1 & 13 & $0(0.0)$ & $13(100)$ & 0 & 0.050 \\
\hline $2-5$ & 51 & $11(21.57)$ & $40(78.43)$ & 1 & - \\
\hline $5-15$ & 62 & $30(48.39)$ & $32(51.61)$ & $2.24(1.35-3.12)$ & 0.005 \\
\hline Not specified & 87 & $15(17.24)$ & $72(82.75)$ & & \\
\hline \multicolumn{6}{|c|}{ Use of contraceptive } \\
\hline Yes & 42 & $15(35.71)$ & $27(64.29)$ & $1.88(0.59-3.16)$ & 0.679 \\
\hline No & 122 & $23(18.85)$ & $99(81.15)$ & 1 & - \\
\hline Not specified & 49 & $18(36.73)$ & $31(63.27)$ & & \\
\hline
\end{tabular}

${ }^{\mathrm{a}}$ Reference category. ${ }^{\mathrm{b}}$ Cumulative sexual partner. 
TABLE 3: Distribution of ICC patients according to FIGO stage, degree of differentiation, and HIV status in bivariate analysis.

\begin{tabular}{|c|c|c|c|c|c|}
\hline \multirow[b]{2}{*}{ Variables } & \multicolumn{3}{|c|}{ HIV status } & \multirow[b]{2}{*}{ OR $(95 \% \mathrm{CI})$} & \multirow[b]{2}{*}{$P$ value } \\
\hline & $\begin{array}{c}\text { Total } \\
N=213\end{array}$ & $\begin{array}{c}\mathrm{HIV+} \\
N=56 \\
n(\%)\end{array}$ & $\begin{array}{c}\text { HIV- } \\
N=157 \\
n(\%)\end{array}$ & & \\
\hline \multicolumn{6}{|l|}{ FIGO stages } \\
\hline Stage I & 57 & $11(19.30)$ & $46(80.7)$ & $1.04(0.44-1.63)$ & 0.969 \\
\hline Stage II & 65 & $12(18.46)$ & $53(81.54)$ & $1^{\mathrm{a}}$ & - \\
\hline Stage III & 60 & $25(41.67)$ & $35(58.33)$ & $2.25(0.96-3.54)$ & 0.421 \\
\hline Stage IV & 23 & $7(30,43)$ & $16(69.57)$ & $1.64(0.70-2.58)$ & 0.115 \\
\hline Not specified & 8 & $1(12.5)$ & $7(87.5)$ & & \\
\hline \multicolumn{6}{|c|}{ Degree of differentiation } \\
\hline Grade I & 50 & $5(10)$ & $45(90)$ & 1 & - \\
\hline Grade II & 62 & $26(41.94)$ & $36(58.06)$ & $4.19(3.16-5.21)$ & 0.041 \\
\hline Grade III & 26 & $20(72.96)$ & $6(27.04)$ & $7.69(5.80-9.57)$ & 0.005 \\
\hline Not specified & 75 & $5(6.67)$ & $70(93.33)$ & & \\
\hline
\end{tabular}

${ }^{\text {a }}$ Reference category.

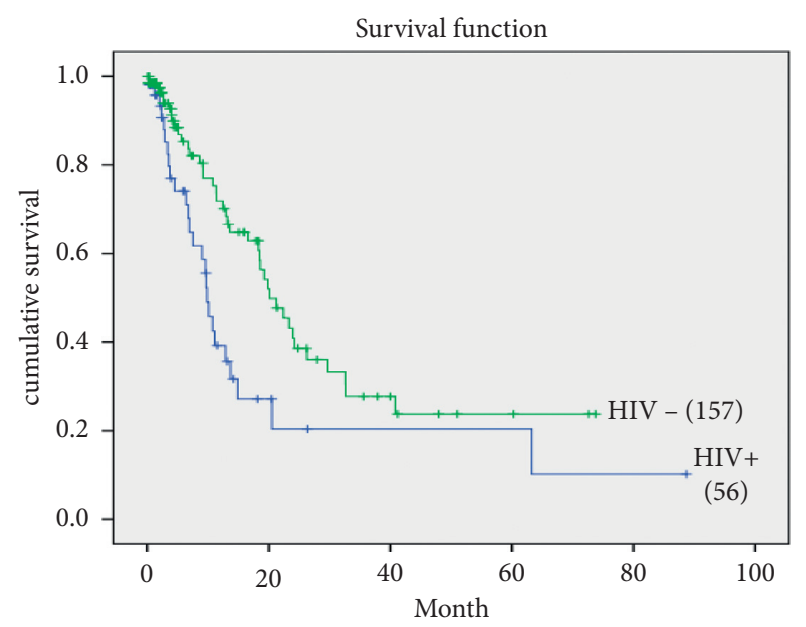

FIgURE 1: Survival curve according to HIV status.

invasive cervical cancer. Several studies have analyzed the HIV prevalence in invasive cervical cancer patients. Some findings are similar to ours, with proportions of 21 and $25 \%$ $[13,14]$. Others found proportions higher than ours (29.7-66.4\%) [15-20]. A study in Botswana reported a prevalence of $66.4 \%$ [18]. These differences may be due to the fact that HIV prevalence in women in Cameroon $3.6 \%$ according to the latest Demography Health Survey) is lower than HIV prevalence in Botswana (23.4\% in 2013, according to the UNAIDS report) $[12,21]$.

As for the factors associated with HIV+ status, we found that, compared to older women (40-60 years), younger ones ( $<40$ years) had twice the risk of being HIV+ (OR: 2.03 (1.38-2.67)). Our findings may be due to the fact that HIV infection accelerates the development of precancerous lesions to invasive cancer. These findings corroborate those of many other authors related to the young age of HIV+ patients with cervical cancer at diagnosis. A study in Tanzania revealed findings similar to ours. They found that young patients with invasive cervical cancer under 50 years were more likely to be HIV+ [20].

Single women were more likely to be HIV+ among ICC patients (OR: 2.88 (1.58-4.17)). Similarly, separated/ divorced women were more likely to have increased risk of being HIV+ (OR: 3.08 (1.69-4.46)). These findings may be partly due to the fact that people not involved in a stable exclusive relation are much more exposed to HIV. This report on separated/divorced status is similar to that of the 2011 DHS-MICS; HIV prevalence was highest in widows (17.9\%) and divorcees (15.7\%) [22].

Compared to patients living in rural areas, those living in urban ones were more likely to be HIV+ (OR: 3.66; 95\% CI: 1.14-6.17). These findings corroborate those of the 2018 HDS-MICS, which reported the higher HIV prevalence in women living in urban areas compared to those living in rural ones (3.9\% vs. 2.9\%) [12].

As for parity, our findings revealed that women of low parity were more likely to be $\mathrm{HIV}+$. These findings may be due to the fact that HIV+ status could decrease the desire for maternity in some women. This could also be due to the fact that ICC occurs more in HIV+ women at a younger age [8].

Women with a history of cumulated sexual partners (CSP) $\geq 5$ were more likely to be $\mathrm{HIV}+$, compared to those with less than 5 CSP (OR: 2.24 (1.35-3.12)). These findings may be due to the fact that a history of many sexual partners is a common risk factor for HIV and ICC [2]. These findings are similar to those of a study in Tanzania that reported a history of many sexual partners as a factor associated with HIV+ status (>6) (OR: 5.56; 95\% CI: 1.18-26.25) [20].

$\mathrm{HIV}+$ patients mostly came with stages III-IV and grades II and III (57.15\%). Other authors highlighted the association between HIV and poorly differentiated tumor cells [23]. These findings are similar to those in Tanzania that found the possibility six times greater to be HIV+ in women with tumor poorly differentiated cells than those with good or moderate differentiated ones [24].

In HIV + women, the median of survival was worse than in HIV- ones (9.83 months vs. 20.10 months). Therefore, half of HIV+ patient with ICC died in the same year, before the tenth month; half of HIV- ones died before the second year, at least during the first 20 months. Lower survival rates in $\mathrm{HIV}+$ patients with ICC compared to HIV- ones were underlined by other authors [24-27]. These results may be 
due to the advanced stage at diagnosis and poor cell differentiation in HIV+ patients [24]. HIV+ patients with ICC could die sooner of opportunistic infections probably due to the deteriorating of immune-suppression condition. Our findings are similar to those of Dryden Peterson et al., in 2016 in Botswana, who also found that HIV+ patients had a shorter median survival than HIV- ones (21.7 months vs. 30.5 months), i.e., a 9-month difference between the 2 groups [18].

Median's survival of HIV + and HIV - found in our study are 12 months lower than those found in Botswana. This significant difference may be due to different therapeutic modalities in each of the two countries, grades disparity of tumoral differentiation and treatment compliance.

\section{Conclusion}

HIV infection prevalence is high in patients with ICC $(24.67 \%) . \mathrm{HIV}+$ patients with ICC are younger, most often received advanced stages III-IV, and have mostly poorly differentiated cells. HIV+ patients with ICC have survival median lower than HIV- ones. We emphasize on the need to create multidisciplinary care units for people living with $\mathrm{HIV}+$ including cervical cancer prevention.

\section{Data Availability}

The data used to support the findings of this study are available from the corresponding author upon request.

\section{Conflicts of Interest}

The authors declare that they have no conflicts of interest.

\section{Authors' Contributions}

Pierre Marie Tebeu initiated the study, analyzed data, supervised, and wrote the article. Laure Leka Zingué drafted the protocol and collected and analyzed data. Jesse Saint Saba Antaon analyzed data and wrote and submitted the article. Etienne Okobalemba Atenguena and Julius Sama Dohbit corrected the protocol and supervised data collection. Jean Pierre Ngou-Mve-Ngou critically reviewed the article.

\section{Acknowledgments}

The authors are grateful to Yaoundé University Hospital, Yaoundé General Hospital (HGY), Yaoundé Gyneco-Obstetric and Pediatric Hospital (YGOPH), Centre's users, and health workers who made possible the implementation of this study.

\section{References}

[1] N. Bhatla, D. Aoki, D. N. Sharma, and R. Sankaranarayanan, "Cancer of the cervix uteri," International Journal of Gynecology \& Obstetrics, vol. 143, pp. 22-36, 2018.

[2] OMS, "La lutte contre le cancer du col de l'utérus: guide des pratiques essentielles," https://apps.who.int/iris/bitstream/ handle/10665/254713/9789242548952-fre.pdf;
jsessionid=BAD22FC127DBA0508368444E8CFCF4CE? sequence $=1$.

[3] F. Bray, J. Ferlay, I. Soerjomataram, R. L. Siegel, L. A. Torre, and A. Jemal, "Global cancer statistics 2018: GLOBOCAN estimates of incidence and mortality worldwide for 36 cancers in 185 countries," CA: A Cancer Journal for Clinicians, vol. 68, no. 6, pp. 394-424, 2018.

[4] P. S. Moore and Y. Chang, "Why do viruses cause cancer? Highlights of the first century of human tumour virology," Nature Reviews Cancer, vol. 10, no. 12, pp. 878-889, 2010.

[5] P. Memiah, V. Makokha, W. Mbuthia et al., "Epidemiology of cervical squamous intraepithelial lesions in HIV infected women in Kenya: a cross-sectional study," African Journal of Reproductive Health, vol. 19, no. 1, pp. 133-139, 2015.

[6] E. Orock Ge and D. As, "Current cancer incidence and trends in Yaounde, Cameroon," Oncology, Gastroenterology and Hepatology Reports, vol. 1, no. 1, pp. 58-63, 2012.

[7] L. S. Massad, X. Xie, G. D'Souza et al., "Incidence of cervical precancers among HIV-seropositive women," American Journal of Obstetrics and Gynecology, vol. 212, no. 5, pp. 606-608, 2015.

[8] S. Kapambwe, V. V. Sahasrabuddhe, M. Blevins, M. H. Mwanahamuntu, V. Mudenda, and B. E. Shepherd, "Implementation and operational research: age distribution and determinants of invasive cervical cancer in a "screen-andtreat" program integrated with HIV/AIDS care in Zambia," Journal of Acquired Immune Deficiency Syndromes, vol. 70, no. 1, pp. e20-6, 1999.

[9] U. Ononogbu, M. Almujtaba, F. Modibbo et al., "Cervical cancer risk factors among HIV-infected Nigerian women," BMC Public Health, vol. 13, no. 1, p. 582, 2013.

[10] P.-M. Tebeu, P. Petignat, and P. Mhawech-Fauceglia, "Gynecological malignancies in maroua, Cameroon," International journal of gynaecology and obstetrics, vol. 104, 2009.

[11] Z. Sando, J. T. Fouogue, F. Y. Fouelifack, J. H. Fouedjio, E. T. Mboudou, and J. L. O. Essame, "Profile of breast and gynecological cancers in Yaoundé-Cameroon," The Pan African Medical Journal, vol. 17, p. 28, 2014.

[12] Institut National de la Statistique, "Enquête démographique et de santé et à indicateurs multiples eds-mics, cameroun," 2018, https://dhsprogram.com/pubs/pdf/PR116/PR116.pdf.

[13] M. Moodley, J. Moodley, and I. Kleinschmidt, "Invasive cervical cancer and human immunodeficiency virus (HIV) infection: a South African perspective," International Journal of Gynecological Cancer, vol. 11, no. 3, pp. 194-197, 2001.

[14] A. Jaquet, Cancers du col de l'Utérus et Infection à VIH en Afrique de l'Ouest: Epidémiologie Descriptive, Déterminants et Dépistage, Vol. 2, Univerisite Bordeaux Segalen, Bordeaux, France, 2012.

[15] A. Ntekim, "Cervical cancer in sub sahara Africa," Top Cervical Cancer Advocacy Preview Intech, vol. 51, 2012.

[16] J. Ferlay, I. Soerjomataram, R. Dikshit et al., "Cancer incidence and mortality worldwide: sources, methods and major patterns in GLOBOCAN 2012," International Journal of Cancer, vol. 136, no. 5, pp. E359-E386, 2015.

[17] H. L. White, C. Mulambia, M. Sinkala et al., "“Worse than HIV" or "not as serious as other diseases"? Conceptualization of cervical cancer among newly screened women in Zambia," Social Science \& Medicine, vol. 74, no. 10, pp. 1486-1493, 2012.

[18] S. Dryden-Peterson, M. Bvochora-Nsingo, G. Suneja et al., "HIV infection and survival among women with cervical cancer," Journal of Clinical Oncology, vol. 34, no. 31, pp. 3749-3757, 2016. 
[19] S. Kapambwe, V. V. Sahasrabuddhe, M. Blevins et al., "Implementation and operational research," JAIDS Journal of Acquired Immune Deficiency Syndromes, vol. 70, no. 1, pp. e20-e26, 2015.

[20] D. Matovelo, M. Magoma, P. Rambau, A. Massinde, and N. Masalu, "HIV serostatus and tumor differentiation among patients with cervical cancer at Bugando Medical Centre," BMC Research Notes, vol. 5, no. 1, p. 406, 2012.

[21] O. SIDA, "Rapport sur l'épidémie mondiale," 2015, https:// www.infectiologie.com/UserFiles/File/formation/desc/2017/ seminaire-janvier-2017/cours-mercredi-01.02/vers-la-fin-dusida-en-2030-c-arvieux.pdf.

[22] Institut National de la Statistique, "Enquête démographique et de santé et à indicateurs multiples eds-mics, cameroun," 2011, https://dhsprogram.com/pubs/pdf/fr260/fr260.pdf4.

[23] P. B. Gichangi, J. Bwayo, B. Estambale et al., "Impact of HIV infection on invasive cervical cancer in Kenyan women," AIDS, vol. 17, no. 13, pp. 1963-1968, 2003.

[24] M. Maiman, R. G. Fruchter, L. Guy, S. Cuthill, P. Levine, and E. Serur, "Human immunodeficiency virus infection and invasive cervical carcinoma," Cancer, vol. 71, no. 2, pp. 402-406, 1993.

[25] P. Lomalisa, T. Smith, and F. Guidozzi, "Human immunodeficiency virus infection and invasive cervical cancer in South Africa," Gynecologic Oncology, vol. 77, no. 3, pp. 460-463, 2000.

[26] J. Musa, J. Nankat, C. J. Achenbach, I. H. Shambe, B. O. Taiwo, and B. Mandong, "Cervical cancer survival in a resourcelimited setting-North Central Nigeria," Infectious Agents and Cancer, vol. 11, no. 1, 2015, http://www.infectagentscancer. com/content/11/1/15.

[27] L. Tawe, E. MacDuffie, M. Narasimhamurthy, Q. Wang, S. Gaseitsiwe, and S. Moyo, "Human papillomavirus genotypes in women with invasive cervical cancer with and without human immunodeficiency virus infection in Botswana," International Journal of Cancer, vol. 146, 2019. 